Supplement of Earth Surf. Dynam., 4, 407-423, 2016

http://www.earth-surf-dynam.net/4/407/2016/

doi:10.5194/esurf-4-407-2016-supplement

(C) Author(s) 2016. CC Attribution 3.0 License.

(c) (1)

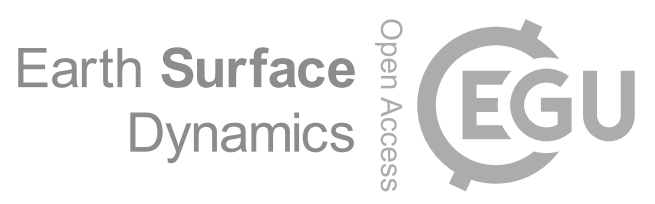

Supplement of

\title{
Modeling long-term, large-scale sediment storage using a simple sediment budget approach
}

Victoria Naipal et al.

Correspondence to: Victoria Naipal (victoria.naipal@ mpimet.mpg.de)

The copyright of individual parts of the supplement might differ from the CC-BY 3.0 licence. 


\section{S1 Derivation of the rainfall erosivity factor for the last millennium}

The $R$ factor of the adjusted RUSLE model is calculated according to the regression equations for different climate zones of the Köppen-Geiger climate classification (Peel et al., 2007) as presented in the study of Naipal et al. (2015). The regression operates on one or more of the following parameters: total annual precipitation, mean elevation, and the simple precipitation intensity index, SDII. In order to calculate the $R$ factor with this method for the last millennium (850-2005AD), we need climate classification maps for this period. As there are to our knowledge no global climate classification maps using the criteria of the Köppen-Geiger climate classification for this long time period, we developed climate classification maps for each century starting from 850AD using climate data from

10 MPI-ESM. Here we used mean precipitation and temperature data from the low-resolution version of MPI-ESM from the last millennium experiment. The derivation of climate classification maps for the last millennium based on the data of a global climate model is a new aspect of this study. Figures S1a, $\mathrm{S} 1 \mathrm{~b}$, and S1c show the global climate zones of respectively, the period 850-950AD using climate data from MPI-ESM, present day using climate data from MPI-ESM, and present day from Peel et al. (2007). The map for present day based on data from MPI-ESM differs to a certain extend from the map of Peel et al. (2007) for certain regions such as western Europe, where the models show biases in precipitation amounts. However, the main global variability in the climate zones is captured. Using climate data of MPI-ESM to calculate the $R$ factor we found that the $R$ values for the Rhine catchment are overestimated by a factor of 5 when compared to the $R$ values calculated with 20 data from the Global Precipitation Climatology Centre (GPCC) product (Meyer-Christoffer et al. 2011) for the period 1950-2000AD. This overestimation is mainly due to the strong overestimation in precipitation rates for West-Europe by MPI-ESM. Therefore, we introduced a constant correction factor based on the $R$ values calculated from observational datasets. We estimated this correction factor by dividing the $R$ values based on data from MPI-ESM by the $R$ values based on observational datasets.

\section{S2 Derivation of the land cover factor for the last millennium}

Due to the lack of data on the normalized difference vegetation index (NDVI), the method presented in the study of Naipal et al. (2015) for estimation of the $C$ factor of the adjusted RUSLE model could not be used in this study. Instead, a new method was developed based on the $C$ values provided by Panagos et al. (2015) for Europe for different land cover types, combined with the fractions of land cover, and the leaf area index ( $L A I)$ from MPI-ESM. The $L A I$ is used to estimate the percentage vegetation cover $(c f)$, which has been shown to influence the overall value of the $C$ factor for a specific land cover type (United States Department of Agriculture, 1978). The $c f$ (dimensionless) is estimated according to Beer's Law approximation:

$c f=1-e^{\{-0.5 L A I\}}$

Four $c f$ classes are distinguished: $\leq 0.2,0.2$ to $0.45,0.45$ to 0.75 , and $>0.75$. The range in $C$ factors for the different land cover types used in this study is given in table S2. If the $c f$ was smaller than 0.2 , all land cover types, except bare soil, were given a maximum value of 0.45 . This value corresponds to the maximum $C$ values found by United States Department of Agriculture (1978) and Panagos et al. (2015). For bare soil the maximum $C$ value was somewhat higher in comparison to the other land cover types according to Panagos et al. (2015).

\section{S3 Derivation of the other RUSLE factors}

The $K$ factor ( $\mathrm{t}$ ha h ha ${ }^{-1} \mathrm{MJ}^{-1} \mathrm{~mm}^{-1}$ ) of the adjusted RUSLE model is calculated using 30 arcsec soil data on sand, silt, clay fractions and percent organic matter (from Global Soil Data set for use 
in Earth System Models (GSCE), (Shangguan et al., 2014)), according to the method of Torri et al. (1997):

$K=0.0293\left(0.65-D g+0.24 D g^{2}\right) * e^{\left(-0.0021 \frac{O M}{f_{\text {clay }}}-0.00037\left(\frac{O M}{f_{\text {clay }}}\right)^{2}-4.02 f_{\text {clay }}+1.72 f_{\text {clay }}^{2}\right)}$

where Dg is defined as:

$D g=-3.5 f_{\text {sand }}-2 f_{\text {silt }}-0.5 f_{\text {clay }}$

Where, $f_{\text {sand }}, f_{\text {silt }}$ and $f_{\text {clay }}$ are the fractions of respectively sand (particle size of 0.05-2 mm), silt (particle size of 0.002-0.05 mm) and clay (particle size of 0.00005-0.002 mm). OM is the percent organic matter. Volcanic soils are defined as Andosols according to the FAO 90 in the Harmonized World Soil Database (HWSD), and are given a $K$ factor value of 0.08 . To account for the effect of stoniness on soil erosion we reduced the total erosion by $30 \%$ for areas with a gravel percentage larger or equal to $30 \%$ for nonagricultural land (Cerdan et al., 2010). For agricultural and grassland areas we reduced soil erosion by $80 \%$ in areas where the gravel percentage exceeded $12 \%$ (Doetterl] et al., 2012).

The $S$ factor of the adjusted RUSLE model is computed by the continuous function of Nearing (1997):

$60 S=1.5+\frac{17}{1+e^{(2.3-6.1 * \sin \theta)}}$.

in which $\theta$ is the percent slope that is derived from a $1 \mathrm{~km}$ digital elevation model (DEM) and scaled to a resolution of $150 \mathrm{~m}$ according to the fractal method presented by Naipal et al. (2015).

\section{S4 Derivation of accurate flow directions on a 5 arcmin resolution}

To get accurate flow directions we used the DEM and flow-accumulation on 30 arcsec from the HydroSHEDS (Hydrological data and maps based on SHuttle Elevation Derivatives at multiple Scales) database (Lehner et al. 2006). The HydroSHEDS DEM is based on SRTM and GTOPO30 data. The HydroSHEDS flow-accumulation data for the Rhine catchment was aggregated to 5 arcmin, and the inverted upscaled flow-accumulation values were then used as input for the multiple flow routing scheme. It should be mentioned that using a coarser resolution DEM for the sediment routing results in strongly biased flow directions. 


\section{References}

Cerdan, O., Govers, G., Le Bissonnais, Y., Van Oost, K., Poesen, J., Saby, N., Gobin, a., Vacca, a., Quinton, J., Auerswald, K., Klik, a., Kwaad, F., Raclot, D., Ionita, I., Rejman, J., Rousseva, S., Muxart, T., Roxo, M., and Dostal, T.: Rates and spatial variations of soil erosion in Europe: A study based on erosion plot data, Geomorphology, 122, 167-177, doi 10.1016/j.geomorph.2010.06.011, http://linkinghub.elsevier.com/ retrieve/pii/S0169555X10002813, 2010.

Doetterl, S., Van Oost, K., and Six, J.: Towards constraining the magnitude of global agricultural sediment and soil organic carbon fluxes, Earth Surface Processes and Landforms, 37, 642-655, doi 10.1002/esp.3198. http://doi.wiley.com/10.1002/esp.3198. 2012.

80 Lehner, B., Verdin, K., and Jarvis, A.: HydroSHEDS, pp. 1-27, 2006.

Meyer-Christoffer, A., Becker, A., Finger, P., Rudolf, B., Schneider, U., and Ziese, M.: GPCC Climatology Version 2011 at $0.25^{\circ}$ : Monthly Land-Surface Precipitation Climatology for Every Month and the Total Year from Rain-Gauges built on GTS-based and Historic Data, doi:10.5676/DWD_GPCC/CLIM_M_V2011_025. 2011.

85 Naipal, V., Reick, c., Pongratz, J., and Van Oost, K.: Improving the global applicability of the RUSLE model adjustement of the topographical and rainfall erosivity factors, Geoscientific Model Development, pp. 1-22, doi $10.5194 /$ gmd-8-1-2015 2015.

Nearing, M. A.: A single continues function for slope steepness influence on soil loss, Soil Science Society of America, 61, 1997.

90 United States Department of Agriculture, U. S. D. A.: PREDICTING RAINFALL EROSION LOSSES. A GUIDE TO CONSERVATION PLANNING, Science and Education Administration, 1978.

Panagos, P., Borrelli, P., Meusburger, K., Alewell, C., Lugato, E., and Montanarella, L.: Estimating the soil erosion cover-management factor at the European scale, Land Use Policy, 48, 3850, doi 10.1016/j.landusepol.2015.05.021, http://linkinghub.elsevier.com/retrieve/pii/S0264837715001611. 2015.

Peel, M. C., Finlayson, B. L., and Mcmahon, T. A.: Updated world map of the Koeppen-Geiger climate classification, Hydrology and Earth System Science, 11, 1633-1644, 2007.

Shangguan, W., Dai, Y., Duan, Q., Liu, B., and Yuan, H.: A global soil data set for earth system modeling, Journal of Advances in Modeling Earth Systems, 6, 249-263, doi 10.1002/2013MS000293. 2014.

100 Torri, D., Poesen, J., and Borselli, L.: Predictability and uncertainty of the soil erodibility factor using a global dataset, Catena, 31, 1-22, 1997. 


\section{Figure S1a.}

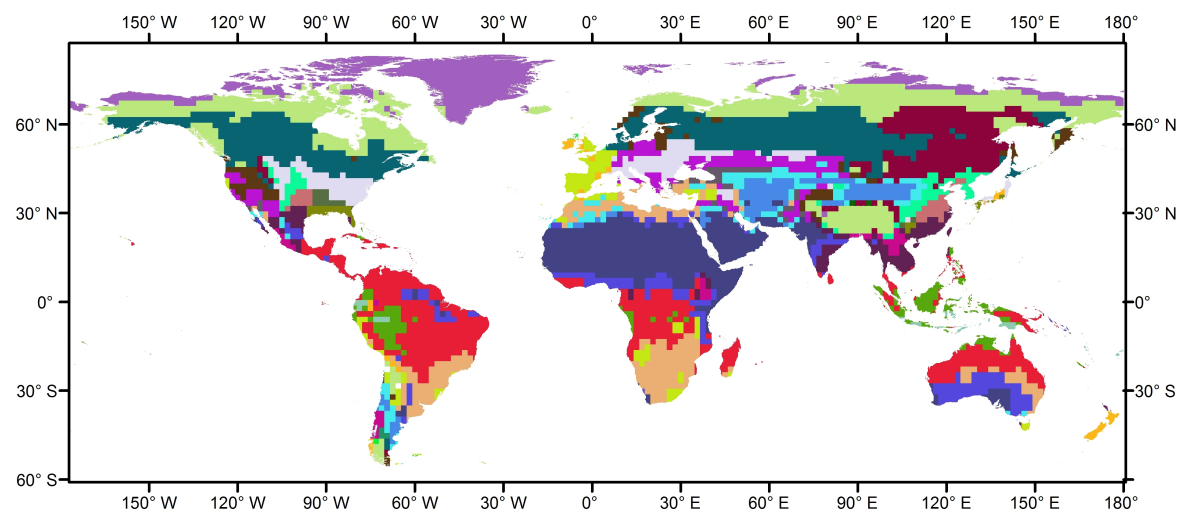

Figure S1b.

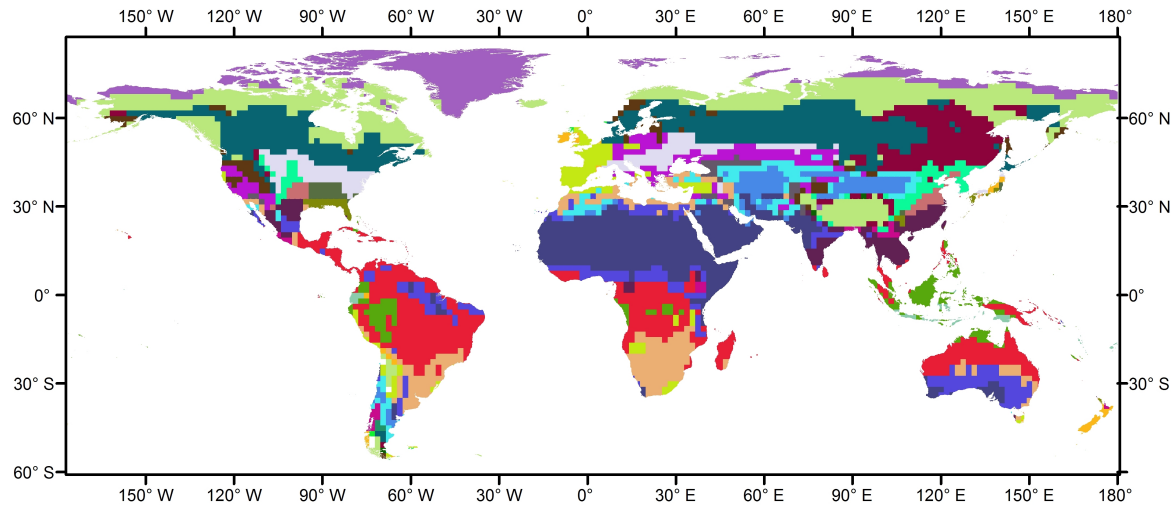

Figure S1c.

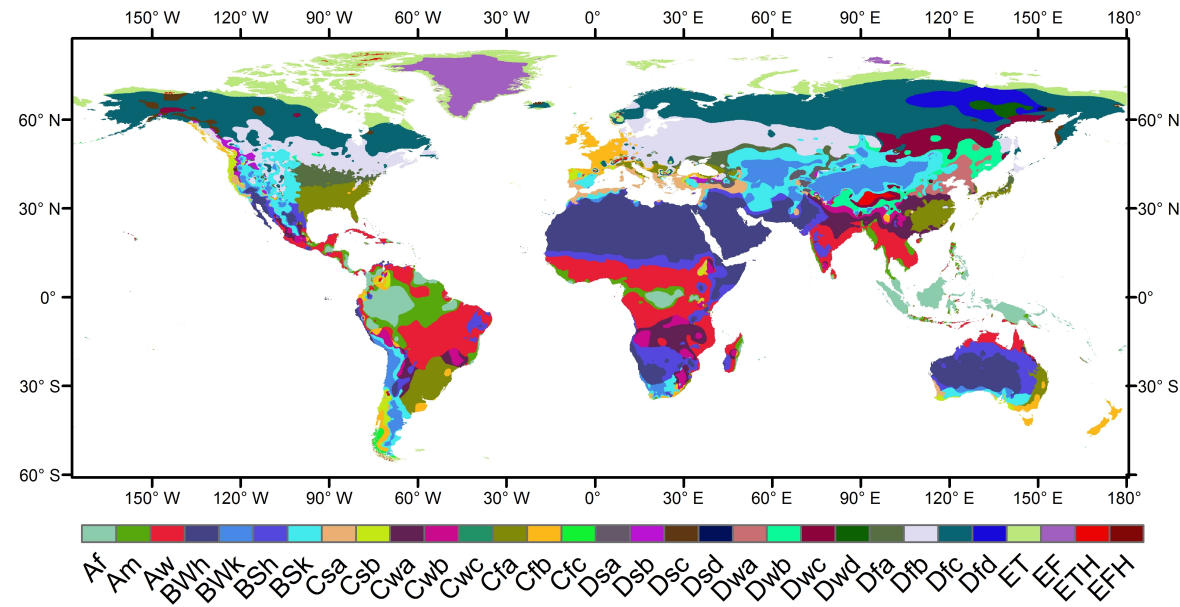

Figure S1. Climate classification maps based on the criteria of the Köppen-Geiger climate classification for (a) the period 850-950AD using data from MPI-ESM, (b) the period 1950-2005AD using data from MPI-ESM, and (c) for present day from Peel et al. (2007). The description of the different climate zone abbreviations can be found in the paper of Peel et al. (2007). 
Table S2. $C$ values for different land cover types and $c f$ classes.

\begin{tabular}{lrrrrrr}
\hline$c f$ & Forest & Shrubs & Grass & Pasture & Crops & Bare soil \\
\hline$>0.75$ & 0.0001 & 0.003 & 0.01 & 0.05 & 0.03 & 0.1 \\
$0.6-0.75$ & 0.00089 & 0.029 & 0.029 & 0.077 & 0.14 & 0.2 \\
$0.45-0.6$ & 0.00168 & 0.0559 & 0.048 & 0.1 & 0.26 & 0.29 \\
$0.2-0.45$ & 0.003 & 0.1 & 0.08 & 0.15 & 0.45 & 0.45 \\
$\leq 0.2$ & 0.45 & 0.45 & 0.45 & 0.45 & 0.45 & 0.55 \\
\hline
\end{tabular}

